\title{
Atypical, bidirectional regulation of cadmium-induced apoptosis via distinct signaling of unfolded protein response
}

\author{
M Yokouchi ${ }^{1}$, N Hiramatsu ${ }^{1}$, K Hayakawa ${ }^{1}$, A Kasai ${ }^{1}$, Y Takano ${ }^{1}$, J Yao ${ }^{1}$ and M Kitamura*,1
}

Cadmium is a widely distributed nephrotoxic metal that causes renal tubular injury. In this report, we investigated involvement of endoplasmic reticulum (ER) stress and individual unfolded protein responses in cadmium-initiated apoptosis of tubular epithelial cells. Cadmium chloride $\left(\mathrm{CdCl}_{2}\right)$ induced expression of endogenous ER stress markers, GRP78, GRP94 and CHOP in vitro and in vivo, and subsequently caused cytological changes typical of apoptosis. Attenuation of ER stress by transfection with ER chaperone GRP78 or ORP150 suppressed $\mathrm{CdCl}_{2}$-triggered apoptosis. In response to $\mathrm{CdCl}_{2}$, phosphorylation of RNAdependent protein kinase-like ER kinase (PERK) and eukaryotic translation initiation factor $2 \alpha$ (elF2 $\alpha$ ) was observed. Enhanced phosphorylation of elF2 $\alpha$ attenuated, whereas inhibition of elF2 $\alpha$ exacerbated $\mathrm{CdCl}_{2}$-induced apoptosis. Activating transcription factor 6 (ATF6) was also activated by $\mathrm{CdCl}_{2}$ and blockade of this process suppressed induction of $\mathrm{CHOP}$ and thereby improved cell survival. $\mathrm{CdCl}_{2}$ also triggered activation of the inositol-requiring ER-to-nucleus signal kinase 1 (IRE1)-X-box-binding protein 1 (XBP1) pathway and inhibition of XBP1 attenuated apoptosis independent of GRP78 and CHOP. C-Jun N-terminal kinase (JNK), another molecule downstream of IRE1, was also phosphorylated by $\mathrm{CdCl}_{2}$ and its inhibition attenuated apoptosis. These results evidenced bidirectional regulation of apoptosis in cadmium-exposed cells. The ATF6 and IRE1 pathways cooperatively caused apoptosis via induction of CHOP, activation of XBP1 and phosphorylation of JNK, and the PERK-elF2 $\alpha$ pathway counteracted the proapoptotic processes.

Cell Death and Differentiation (2007) 14, 1467-1474; doi:10.1038/sj.cdd.4402154; published online 27 April 2007

Exposure to cadmium via drinking water, foods and cigarette smoke causes accumulation of this metal in a variety of organs, especially in the liver and kidney. ${ }^{1,2}$ In particular, the highest concentrations of cadmium are observed in the kidney, the main target of the cadmium-related toxicity. ${ }^{3,4}$ In the kidney, accumulation of cadmium occurs mainly in the proximal tubules and other nephron segments are affected only at later stages of intoxication. ${ }^{5}$

Previous investigations suggested that toxic effects of cadmium on the proximal tubules are caused through several mechanisms. In vitro, short-term exposure of the cells to cadmium caused disruption of tight and gap junctions without cellular death. ${ }^{6,7}$ Longer-term exposure resulted in a decrease in glutathione levels and consequent cellular death, ${ }^{8}$ indicating involvement of oxidative stress. In vivo oral administration of cadmium in beagles caused apoptosis and regeneration in the proximal convoluted tubules where cadmium is localized predominantly. ${ }^{9}$

Although the accumulative evidence for tubulotoxic effects of cadmium, molecular mechanisms involved in its proapop- totic action are still unclear. Although roles of reactive oxygen species (ROS) have been postulated, ${ }^{10}$ involvement of other mechanisms have not been elucidated. Alteration in the levels of $\mathrm{c}-\mathrm{Myc}$ and $\mathrm{Bcl}-2$ is not causative, as shown in previous reports. ${ }^{11,12}$ Recently, Xie et al. ${ }^{13}$ reported that cadmium suppressed activity of nuclear factor- $\kappa \mathrm{B}$, a well-known antiapoptotic transcription factor, and thereby induced apoptosis of tubular epithelial cells.

Endoplasmic reticulum (ER) stress is involved in the induction of apoptosis that occurs in a wide range of pathological situations including hypoxia and ischemia, viral infection, neurodegenerative disorders, drug-induced tissue injury and metabolic diseases such as diabetes mellitus. ${ }^{14,15}$ In the central nervous system, some previous reports suggested a possibility that heavy metals may induce ER stress. For example, manganese, lead and mercury induced expression of $78 \mathrm{kDa}$ glucose-regulated protein (GRP78), a marker of ER stress, in cultured dopaminergic neuronal cells, astrocytes and glioma cells, respectively. ${ }^{16-18}$ Recently, it has been reported that ER stress was involved in

\footnotetext{
1'Department of Molecular Signaling, Interdisciplinary Graduate School of Medicine and Engineering, University of Yamanashi, Chuo, Yamanashi 409-3898, Japan ${ }^{*}$ Corresponding author: M Kitamura, Department of Molecular Signaling, Interdisciplinary Graduate School of Medicine and Engineering, University of Yamanashi, Chuo, Yamanashi 409-3898, Japan. Tel: + 8155273 8054; Fax: + 8155273 8054; E-mail: masanori@yamanashi.ac.jp

Keywords: cadmium; renal tubular cell; apoptosis; endoplasmic reticulum stress; unfolded protein response

Abbreviations: ROS, reactive oxygen species; ER, endoplasmic reticulum; GRP, glucose-regulated protein; UPR, unfolded protein response; PERK, RNA-dependent protein kinase-like ER kinase; ATF6, activating transcription factor 6; IRE1, inositol-requiring ER-to-nucleus signal kinase 1; elF2 $\alpha$, eukaryotic translation initiation factor $2 \alpha$; XBP1, X-box-binding protein 1; ERSE, ER stress response element; CHOP, CCAAT/enhancer-binding protein-homologous protein; GADD153, growth arrest and DNA damage-inducible protein 153; TRAF2, tumor necrosis factor receptor-associated factor 2; ASK1, apoptosis signal-regulating kinase 1; JNK, c-Jun N-terminal kinase; ES-TRAP, ER stress-responsive alkaline phosphatase; TUNEL, terminal deoxynucleotidyl transferase-mediated dUTP nick-end labeling; ORP150, $150 \mathrm{kDa}$ oxygen-regulated protein; EGFP, enhanced green fluorescence protein; AEBSF, 4-(2-aminoethyl)benzenesulfonyl fluoride; XBP1(U), unspliced form of XBP1; DN, dominant-negative mutant
}

Received 20.10.06; revised 23.3.07; accepted 23.3.07; Edited by A Villunger; published online 27.4.07 
paracetamol- and cisplatin-induced apoptosis of renal tubular cells. ${ }^{19,20}$ However, roles of ER stress in cadmium-induced renal tubular injury have not been disclosed yet.

ER stress is defined as accumulation of unfolded or misfolded proteins in the ER, which induces a coordinated adaptive program called unfolded protein response (UPR). The UPR alleviates ER stress by suppression of protein synthesis, facilitation of protein folding via induction of ER chaperones (e.g., GRP78) and reinforced degradation of unfolded proteins. If the stress is beyond capacity of the adaptive machinery, cells undergo apoptosis. ${ }^{21}$ Currently, three major transmembrane transducers for sensing ER stress are identified in the ER; RNA-dependent protein kinase-like ER kinase (PERK), activating transcription factor 6 (ATF6) and inositol-requiring ER-to-nucleus signal kinase 1 (IRE1). Activation of PERK leads to phosphorylation of the eukaryotic translation initiation factor $2 \alpha$ (elF2 $\alpha$ ), which causes general inhibition of protein synthesis. In response to ER stress, p90ATF6 transits to the Golgi where it is cleaved by the proteases S1P and S2P, yielding a free cytoplasmic domain that is an active transcription factor p50ATF6. Similarly, activated IRE1 catalyzes removal of a small intron from the mRNA of the gene encoding X-box-binding protein 1 (XBP1). This splicing event creates a translational frameshift in $X B P 1$ mRNA to produce an active transcription factor. Activated p50ATF6 and XBP1 subsequently bind to the ER stress response element (ERSE) and the UPR element, leading to expression of target genes including ER chaperones GRP78 and GRP94. ${ }^{21}$ Based on this current knowledge, the ATF6 and IRE1-XBP1 pathways are generally regarded as antiapoptotic UPR.

During the UPR, however, distinct death signals, as well as survival signals, may also be transduced. For example, expression of CCAAT/enhancer-binding protein-homologous protein (CHOP) (also called growth arrest and DNA damageinducible protein 153 (GADD153)) is caused by ATF4 that is induced by the PERK-elF2 $\alpha$ pathway. ER stress also activates ER stress-specific caspase-12 (or caspase-4) localized at the ER membrane through an interaction with IRE1 and tumor necrosis factor receptor-associated factor 2 (TRAF2), leading cells to undergo apoptosis. The IRE1TRAF2 interaction also allows for recruitment and activation of apoptosis signal-regulating kinase 1 (ASK1) and downstream C-Jun N-terminal kinase (JNK), which is involved in a variety of apoptotic pathways. ${ }^{21}$ Based on these findings, the PERK-elF2 $\alpha$ and IREI-JNK/caspase-12 pathways have been considered as proapoptotic UPR.

In the present investigation, we first demonstrate that ER stress plays a crucial role in cadmium-induced apoptosis of renal tubular cells. We further examine roles of individual UPR in the regulation of apoptosis and disclose atypical, bidirectional regulation of apoptosis in cadmium-exposed cells.

\section{Results}

Induction of ER stress by cadmium. To examine whether cadmium triggers ER stress in renal tubular cells, we investigated effects of cadmium chloride $\left(\mathrm{CdCl}_{2}\right)$ on the expression of endogenous biomarkers for ER stress.
Exposure of LLC-PK1 cells to $\mathrm{CdCl}_{2}$ resulted in the induction of GRP78, GRP94 and CHOP in a dosedependent manner (Figure $1 \mathrm{a}$ and b). Time-lapse experiments revealed that induction of these transcripts was observed within $1 \mathrm{~h}$ and sustained for at least 5-6h (Figure 1c). The induction of GRP78 mRNA was associated with accumulation of GRP78 protein (Figure 1d). Similarly, induction of GRP78 (and GRP94) was also observed in response to maximum, non-toxic concentrations of $\left(\mathrm{CH}_{3} \mathrm{COO}\right)_{2} \mathrm{~Pb}_{3}, \mathrm{HgCl}_{2}, \mathrm{CuSO}_{4},\left(\mathrm{CH}_{3} \mathrm{COO}\right)_{2} \mathrm{Ni}_{4}$ and $\mathrm{CoCl}_{2}$ (Supplementary Figure $1 \mathrm{a}$ and $\mathrm{b}$ ).

We recently reported that ER stress-responsive alkaline phosphatase (ES-TRAP) is a sensitive, quantitative marker for ER stress. ${ }^{22}$ Activity of ES-TRAP secreted by transfected cells is rapidly and sensitively downregulated in response to ER stress independent of transcriptional regulation. To confirm induction of ER stress by cadmium, ES-TRAP assay was performed. LLC-PK1 cells constitutively producing ESTRAP were treated with $\mathrm{CdCl}_{2}$ for $3 \mathrm{~h}$ and activity of ES-TRAP in culture medium was evaluated. By $\mathrm{CdCl}_{2}$ treatment, activity of ES-TRAP was markedly reduced to $24.7 \%\left(20 \mu \mathrm{M} \mathrm{CdCl}_{2}\right)$ and $15.2 \%\left(50 \mu \mathrm{M} \mathrm{CdCl}_{2}\right)$ versus untreated control $(100 \%)$ (Figure 1e, left). This reduction was not caused by cellular damage, because the number of viable cells estimated by formazan assay was not affected by $\mathrm{CdCl}_{2}$ (Figure 1e, right).

We tested whether cadmium administered in vivo also induces ER stress in the kidney. Mice were injected with $\mathrm{CdCl}_{2}$ intraperitoneally (12 $\mathrm{mg} / \mathrm{kg}$ body weight), and after 8 and $16 \mathrm{~h}$, the renal cortex was subjected to Northern blot analysis. In consistence with the result in LLC-PK1 cells, expression of GRP78 and CHOP was markedly induced after $8 \mathrm{~h}$. This induction was transient and the expression levels were returned to the basal level after $16 \mathrm{~h}$ (Figure 1f).

ER stress-mediated apoptosis after exposure to cadmium. To examine whether induction of ER stress by cadmium is associated with cellular damage, LLC-PK1 cells were exposed to $\mathrm{CdCl}_{2}$ for $6 \mathrm{~h}$ and subjected to phasecontrast microscopy and Hoechst staining. As shown in Figure $2 \mathrm{a}, \mathrm{CdCl}_{2}$ induced detachment and rounding of the cells. Hoechst33258 staining exhibited nuclear condensation typical of apoptosis. Quantitative analysis revealed that this effect was dose-dependent (Figure 2b). Terminal deoxynucleotidyl transferase-mediated dUTP nick-end labeling (TUNEL) assay also confirmed that even after short $(3 \mathrm{~h})$ exposure to $\mathrm{CdCl}_{2}$ the number of TUNEL-positive apoptotic cells substantially increased (Figure 2c).

To examine whether apoptosis caused by cadmium is mediated by ER stress, LLC-PK1 cells were stably transfected with GRP78 and ER stress-resistant LL/GRP78-3 and LL/GRP78-19 cells were established (Figure 3a). Overexpression of GRP78 conferred resistance to tunicamycin-induced damage (Supplementary Figure 2a). Induction of apoptosis was abolished in LL/GRP78 cells when examined by Hoechst staining (Figure 3b). Using these clones, effects of $\mathrm{CdCl}_{2}$ were evaluated. Similar to the response to tunicamycin, $\mathrm{CdCl}_{2}$-induced injury was significantly attenuated in GRP78transfected cells (Supplementary Figure 2b). In contrast to tunicamycin-induced apoptosis, however, the inhibition was partial, approximately $60 \%$ (Figure 3c). Similar results were 


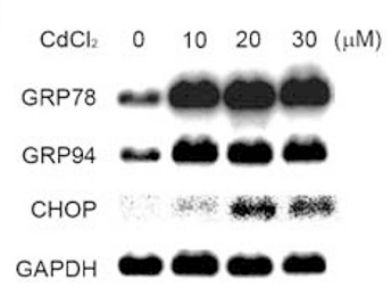

d

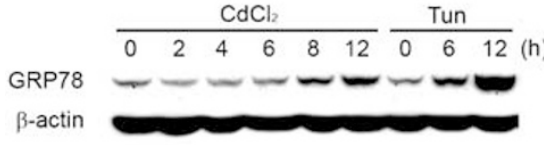

b

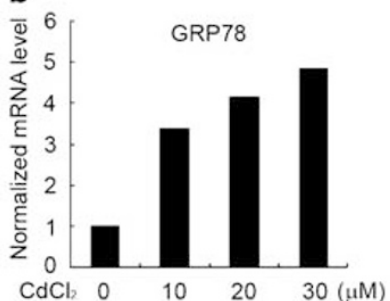

$\mathrm{CdCl}_{2} \quad 0$

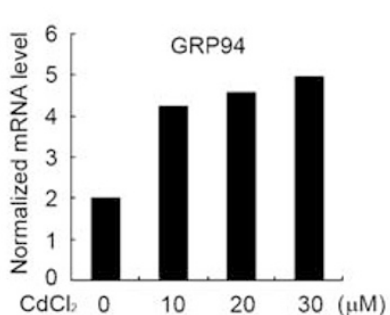

e

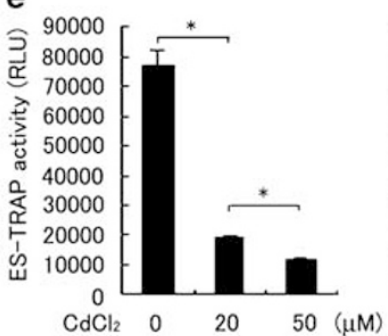

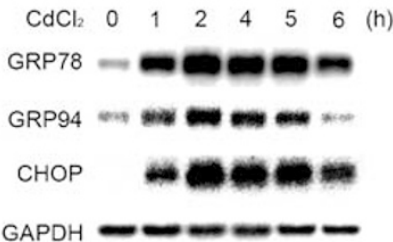

f
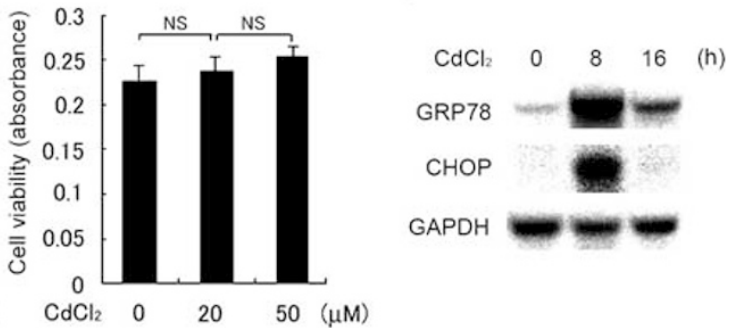

Figure 1 Induction of ER stress by cadmium. (a and $\mathbf{b}$ ) LLC-PK1 cells were treated with $10-30 \mu \mathrm{M} \mathrm{CdCl}$ for $4 \mathrm{~h}$ and expression of GRP78, GRP94 and CHOP was examined by Northern blot analysis. (a) Expression of glyceraldehyde-3-phosphate dehydrogenase (GAPDH) was used as a loading control. The level of individual bands was normalized by the level of GAPDH and the results are shown in (b). (c) Cells were treated with $20 \mu \mathrm{M} \mathrm{CdCl} 2$ for $1-6 \mathrm{~h}$ and subjected to Northern blot analysis. (d) LLC-PK1 cells were treated with $20 \mu \mathrm{M} \mathrm{CdCl}_{2}$ or $5 \mu \mathrm{g} / \mathrm{ml}$ tunicamycin (Tun) for up to $12 \mathrm{~h}$ and subjected to Western blot analysis of GRP78. The level of $\beta$-actin is shown as a loading control. (e) LLC-PK1 cells constitutively producing ES-TRAP were treated with $\mathrm{CdCl}_{2}(20-50 \mu \mathrm{M})$ for $3 \mathrm{~h}$ and activity of ES-TRAP in culture medium was evaluated by chemiluminescent assay (left). At the end of the study, viability of cells was evaluated by formazan assay (right). Data are presented as means $\pm S$.E. Assays were performed in quadruplicate. Asterisks indicate statistically significant differences $(P<0.05)$. NS, not statistically significant. RLU, relative light unit. (f) Mice were administered with $12 \mathrm{mg} / \mathrm{kg}$ body weight of $\mathrm{CdCl}_{2}$ intraperitoneally, and before and after 8 and $16 \mathrm{~h}$, cortexes of the kidneys were subjected to Northern blot analysis of GRP78 and CHOP

obtained in both LL/GRP78-3 and LL/GRP78-19 cells. This result indicated a possibility that cadmium may induce apoptosis through ER stress-dependent and -independent mechanisms.

To confirm our conclusion, we attempted another set of transfection studies using $150 \mathrm{kDa}$ oxygen-regulated protein (ORP150), an ER chaperone that protects cells from ER stress-induced injury. ${ }^{23-25}$ Northern blot analysis confirmed abundant expression of ORP150 in the established clones LL/ORP150-13 and LL/ORP150-20 (Figure 3d). Induction of ER stress by $\mathrm{CdCl}_{2}$ was attenuated in these transfectants when the levels of GRP78 was examined (Figure 3e). In these clones, the apoptogenic effect of $\mathrm{CdCl}_{2}$ was attenuated (Supplementary Figure 2c). The percentages of apoptotic cells evaluated by Hoechst staining decreased from $78.2 \pm 2.3$ to $44.2 \pm 1.7 \% \quad(P<0.05)$ (Figure 3f). Consistent with this result, transient transfection with $O R P 150$ also reduced the percentages of round cells after the treatment with $\mathrm{CdCl}_{2}$ (Supplementary Figure 2d).

Activation of the PERK-elF2 $\alpha$ pathway by cadmium. There are three proximal transmembrane proteins in the ER for sensing of ER stress. The first transducer is PERK, the activation of which leads to phosphorylation of elF2 $\alpha$ and blockade of protein synthesis. ${ }^{21}$ We first examined involvement of the PERKelF2 $\alpha$ pathway in the cadmium-induced apoptosis of tubular epithelial cells. Western blot analysis showed that treatment of LLC-PK1 cells with $\mathrm{CdCl}_{2}$ rapidly induced phosphorylation of PERK and elF $2 \alpha$ within $1 \mathrm{~h}$ (Figures $4 \mathrm{a}, \mathrm{b}$ ). To examine whether this signaling pathway participates in the regulation of apoptosis, salubrinal, a selective inhibitor of elF $2 \alpha$ dephosphorylation, was used to activate the elF2 $\alpha$ pathway. ${ }^{26}$ In LLC-PK1 cells, salubrinal effectively induced phosphorylation of elF2 $\alpha$ (Supplementary Figure 3a). LLC-PK1 cells were then pretreated with or without salubrinal for $1 \mathrm{~h}$, stimulated by $\mathrm{CdCl}_{2}$ for $4 \mathrm{~h}$ and subjected to microscopic analyses. As shown in Supplementary Figure $3 \mathrm{~b}$, salubrinal significantly inhibited $\mathrm{CdCl}_{2}$-induced injury. Hoechst staining showed that the percentage of apoptotic cells was reduced from $90.9 \pm 2.5$ to $63.0 \pm 4.0 \%$ (Figure 4c). Salubrinal alone did not affect the basal cell survival. In this experiment, cadmium-triggered phosphorylation of elF2 $\alpha$ was not obviously enhanced by salubrinal (data not shown). It may be owing to negative feedback via the ATF4-GADD34 pathway that dephosphorylates elF2 $\alpha$.

The PERK-elF2 $\alpha$ pathway has the ability to regulate apoptosis via induction of ATF4 that may affect expression of the proapoptotic gene $C H O P$ or the antiapoptotic gene GRP78. ${ }^{27,28}$ We examined expression of GRP78 and CHOP in $\mathrm{CdCl}_{2}$-stimulated LLC-PK1 cells in the presence or absence of salubrinal. Northern blot analysis revealed that $\mathrm{CdCl}_{2}$ induced both GRP78 and CHOP, whereas expression of these genes was unaffected by salubrinal (Figure 4d). Of note, treatment with salubrinal alone, which caused phosphorylation of elF2 $\alpha$ (Supplementary Figure 3a), also did not upregulate expression of GRP78 and CHOP.

To confirm the antiapoptotic role of the PERK-elF $2 \alpha$ pathway, LLC-PK1 cells were transiently transfected with a gene encoding a dominant-negative mutant of elF2 $\alpha$ together with enhanced green fluorescence protein (EGFP) and exposed to $\mathrm{CdCl}_{2}$ to induce apoptosis. Consistent with the result shown in Figure $4 \mathrm{c}$, dominant-negative inhibition of 
a $\mathrm{CdCl}_{2}$

20
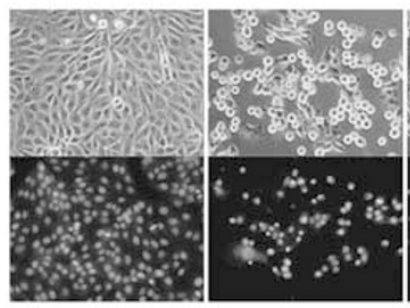

0

$20(\mu \mathrm{M})$

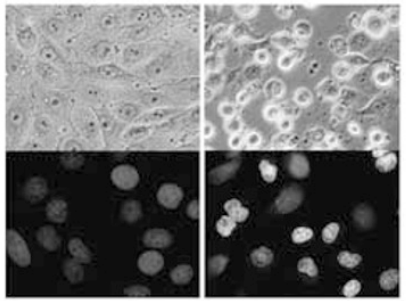

$50 \quad(\mu \mathrm{M})$

b

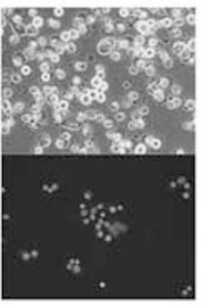

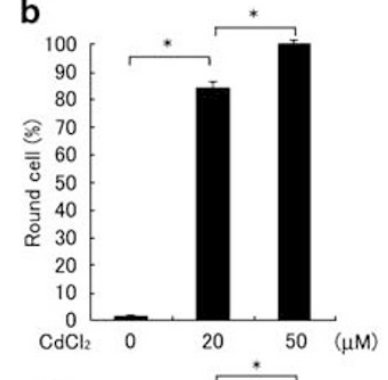

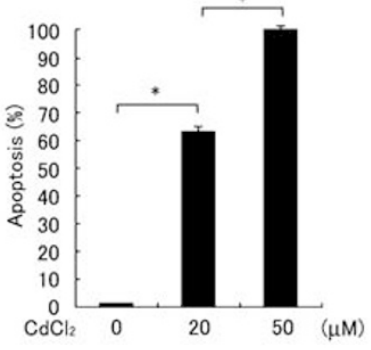

C $\mathrm{CdCl}_{2}$

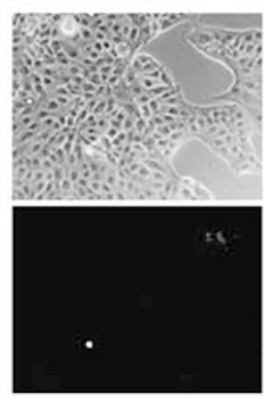

$+$

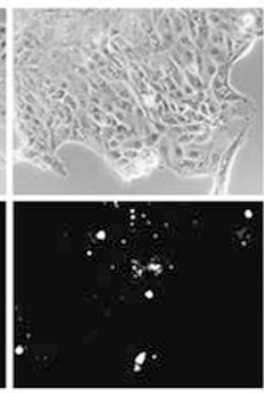

Figure 2 Induction of apoptosis after exposure to cadmium. (a and $\mathbf{b}$ ) LLC-PK1 cells were exposed to 20 or $50 \mu \mathrm{M} \mathrm{CdCl} \mathrm{C}_{2}$ for $6 \mathrm{~h}$ and subjected to phase-contrast microscopy (top) and Hoechst staining (bottom). High-power view of the cells is shown in the lower panel. (b) Percentages of round cells (top) and apoptotic cells (bottom). Data are presented as means \pm S.E. Assays were performed in quadruplicate. Asterisks indicate statistically significant differences $(P<0.05)$. (c) Cells were treated with $20 \mu \mathrm{M} \mathrm{CdCl} 2$ for $3 \mathrm{~h}$ and subjected to phase-contrast microscopy (top) and TUNEL assay (bottom)

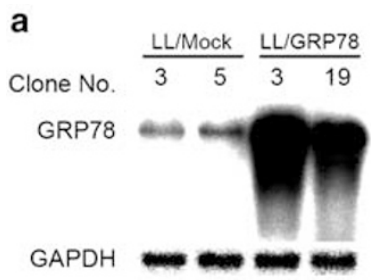

d

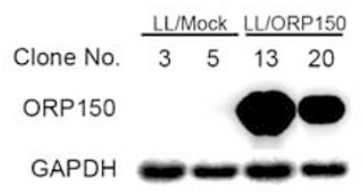

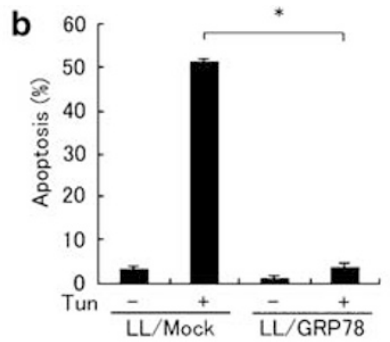

e
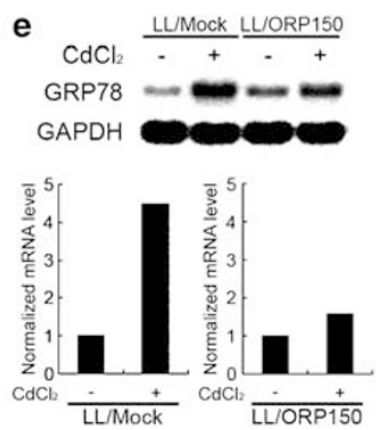

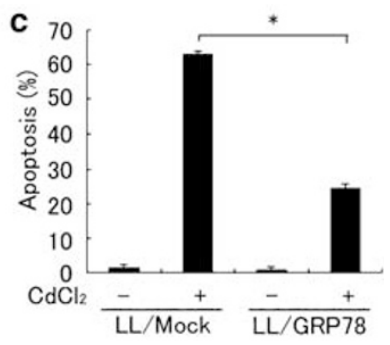

f

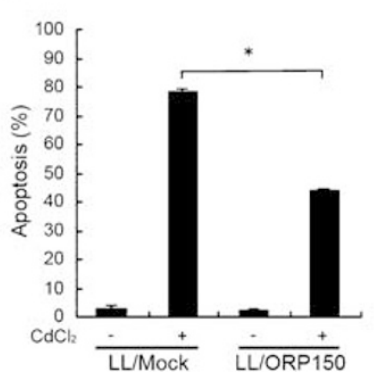

Figure 3 Involvement of ER stress in cadmium-induced apoptosis. LLC-PK1 cells were stably transfected with a gene coding for (a-c) ER chaperone GRP78 or (d-f) ORP150 and LL/GRP78 cells and LL/ORP150 cells were established. (a and d) Northern blot analysis of GRP78 and ORP150 expression in mock-transfected cells (LL/Mock) and established transfectants. (b and c) Cells were treated with (b) $10 \mu \mathrm{g} / \mathrm{ml}$ tunicamycin (Tun) for $6 \mathrm{~h}$ or (c) $20 \mu \mathrm{M} \mathrm{CdCl} 2$ for $4 \mathrm{~h}$ and subjected to fluorescence microscopy. Percentages of apoptotic cells evaluated by Hoechst staining are shown. Asterisks indicate statistically significant differences $(P<0.05)$. (e) Cells were treated with $\mathrm{CdCl}_{2}$ for $4 \mathrm{~h}$ and induction of GRP78 was examined by Northern blot analysis (top) and densitometric analysis (bottom). (f) Cells were treated with $\mathrm{CdCl}_{2}$ for $4 \mathrm{~h}$ and subjected to Hoechst staining to evaluate percentages of apoptotic cells

elF2 $\alpha$ significantly enhanced cadmium-induced apoptosis (Figure 4e).

Activation of the ATF6 pathway by cadmium. We next examined involvement of the ATF6 pathway in the cadmiuminduced apoptosis of tubular cells. LLC-PK1 cells were transiently transfected with FLAG-tagged p90ATF6, exposed to $\mathrm{CdCl}_{2}$ and subjected to Western blot analysis. As shown in Figure $5 \mathrm{a}$, treatment with $\mathrm{CdCl}_{2}$ rapidly caused generation of p50ATF6 within $2 \mathrm{~h}$. To examine whether this signaling pathway is involved in the regulation of apoptosis, a selective inhibitor of ATF6, 4-(2-aminoethyl)benzenesulfonyl fluoride (AEBSF), was used. AEBSF is a serine protease inhibitor and prevents ER stress-induced cleavage of p90ATF6. ${ }^{29}$ 
a
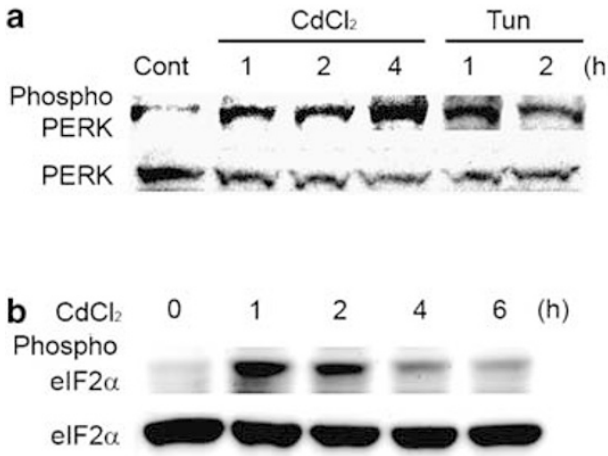

d

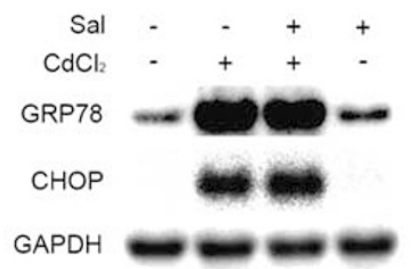

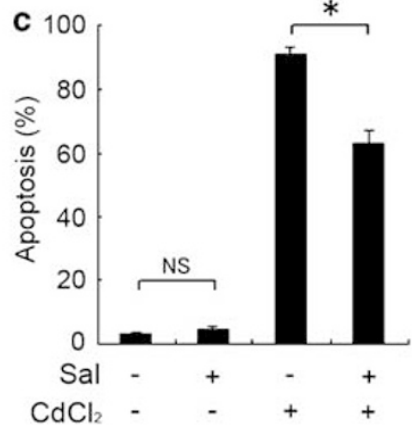

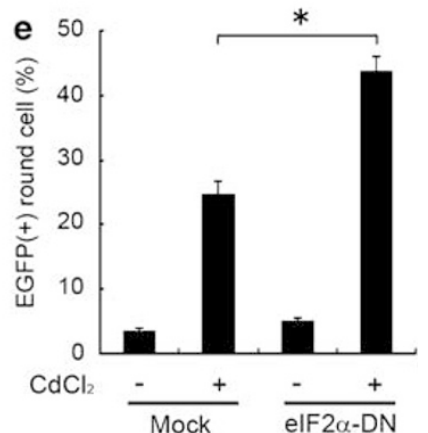

Figure 4 Activation of the PERK-elF2 $\alpha$ pathway by cadmium. (a) LLC-PK1 cells were treated with $20 \mu \mathrm{M} \mathrm{CdCl} 2$ or $10 \mu \mathrm{g} / \mathrm{ml}$ tunicamycin (Tun) for up to $4 \mathrm{~h}$ and phosphorylation of PERK was evaluated by Western blot analysis. Cont, untreated control. (b) Cells were treated with $\mathrm{CdCl}_{2}$ for up to $6 \mathrm{~h}$ and phosphorylation of elF2 $\alpha$ was evaluated by Western blot analysis. (c) LLC-PK1 cells were exposed to $\mathrm{CdCl}_{2}$ in the presence $(+)$ or absence $(-)$ of $50 \mu \mathrm{M}$ salubrinal (Sal) for $4 \mathrm{~h}$ and subjected to Hoechst staining. An asterisk indicates a statistically significant difference $(P<0.05)$. NS, not statistically significant. (d) Cells were exposed to $\mathrm{CdCl}_{2}$ in the presence $(+)$ or absence $(-)$ of salubrinal for $4 \mathrm{~h}$ and subjected to Northern blot analysis. (e) LLC-PK1 cells were transiently transfected with EGFP together with an empty plasmid (Mock) or an expression plasmid for a dominant-negative mutant of elF2 $\alpha$ (elF2 $\alpha$-DN) and exposed to $\mathrm{CdCl}_{2}$ for $4 \mathrm{~h}$. Percentages of EGFP-positive round cells against total EGFP-positive cells were evaluated by fluorescence microscopy. An asterisk indicates a statistically significant difference $(P<0.05)$

Treatment of LLC-PK1 cells with AEBSF abrogated increase of p50ATF6 in response to $\mathrm{CdCl}_{2}$ (Figure $5 \mathrm{~b}$ ). Under this experimental condition, AEBSF inhibited $\mathrm{CdCl}_{2}$-induced injury (Supplementary Figure $3 \mathrm{c}$ ). Quantitative analysis by Hoechst staining showed that AEBSF significantly inhibited cadmium-induced apoptosis in a dose-dependent manner (Figure 5c). To confirm that the ATF6 pathway is proapoptotic, cells were transiently transfected with a gene encoding a dominant-negative mutant of ATF6 together with EGFP and the effect of $\mathrm{CdCl}_{2}$ on apoptosis was retested. As shown in Figure 5d, dominant-negative inhibition of ATF6 significantly suppressed cadmium-induced apoptosis.

It is well known that ATF6 induces expression of ER chaperones via binding to ERSE. ${ }^{30}$ However, the regulatory region of $\mathrm{CHOP}$ also contains ERSE and ATF6 may induce expression of $C H O P$ in some cell types. ${ }^{30}$ We examined a role of the ATF6 pathway in the induction of $\mathrm{CHOP}$ by $\mathrm{CdCl}_{2}$. Northern blot analysis revealed that inhibition of ATF6 by AEBSF blunted induction of $\mathrm{CHOP}$ in response to $\mathrm{CdCl}_{2}$ (Figure $5 \mathrm{e}$ ). Furthermore, transient transfection with a gene coding for a dominant-negative mutant of CHOP significantly attenuated cadmium-induced apoptosis (Figure $5 \mathrm{f}$ ). These results suggested that the ATF6 pathway activated by $\mathrm{CdCl}_{2}$ participated in the induction of apoptosis, at least in part, via induction of $\mathrm{CHOP}$.

Activation of the IRE1-XBP1 pathway and JNK by cadmium. The third proximal transducer for ER stress is IRE1. Activated IRE1 catalyzes removal of a small intron from
$X B P 1$ mRNA, leading to production of the active transcription factor. We first evaluated activation of the IRE1-XBP1 pathway by cadmium using the frameshift of XBP1 as an indicator. LLC-PK1 cells were stably transfected with a gene encoding FLAG-tagged, unspliced form of XBP1 (XBP1(U)) and treated with $\mathrm{CdCl}_{2}$. Abundant expression of XBP1(U) was confirmed by Northern blot analysis (Supplementary Figure 4a). Western blot analysis revealed that $\mathrm{CdCl}_{2}$ rapidly reduced the level of XBP1(U) within $30 \mathrm{~min}$, reached to the bottom at $1 \mathrm{~h}$ and recovered to the basal level after $3 \mathrm{~h}$ (Figure $6 \mathrm{a}$ ).

To examine whether the IRE1-XBP1 pathway is involved in the regulation of apoptosis by $\mathrm{CdCl}_{2}$, LLC-PK1 cells were stably transfected with a gene coding for a dominant-negative mutant of XBP1 (XBP1-DN) and LL/XBP1-DN cells were established. Northern blot analysis confirmed abundant expression of XBP1-DN in the established LL/XBP1-DN-7 and LL/XBP1-DN-20 cells (Figure 6b). Phase-contrast microscopy showed that cadmium-induced injury was significantly attenuated in these LL/XBP1-DN cells (Supplementary Figure 4b). The percentage of apoptotic cells was markedly reduced from $65.0 \pm 2.5$ to $8.6 \pm 1.5 \%(P<0.05)$ by the dominant-negative suppression of XBP1 (Figure 6c). The proapoptotic effect of XBP1 was independent of GRP78 and CHOP because induction of GRP78 and $\mathrm{CHOP}$ by $\mathrm{CdCl}_{2}$ was observed to the same extent in LL/Mock cells and LL/XBP1-DN cells (Figure 6d).

We next examined whether the IRE1-JNK proapoptotic pathway ${ }^{31}$ is involved in the $\mathrm{CdCl}_{2}$-triggered apoptosis of 
a
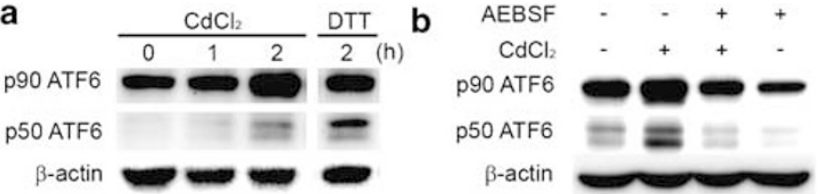

C
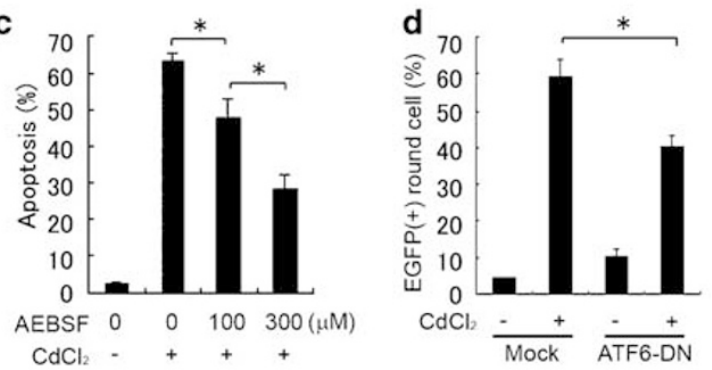

e

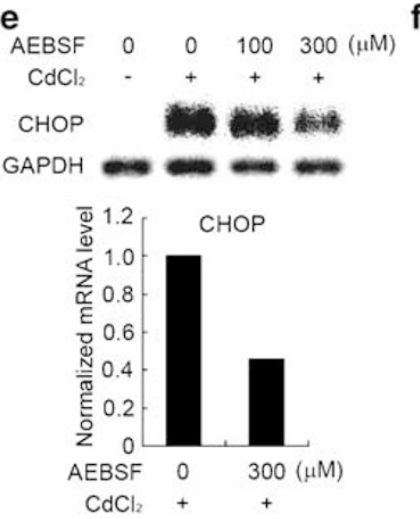

f

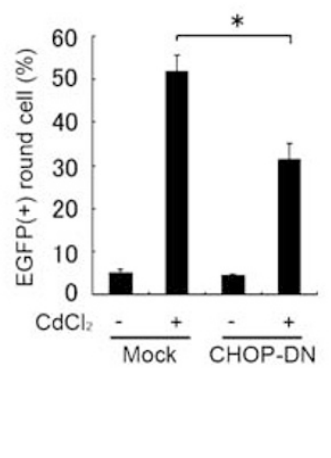

Figure 5 Activation of the ATF6 pathway and consequent induction of $\mathrm{CHOP}$ by cadmium. (a) LLC-PK1 cells transiently transfected with a gene encoding FLAGtagged p90ATF6 were treated with $20 \mu \mathrm{M} \mathrm{CdCl} 2$ or $5 \mathrm{~mm}$ dithiothreitol (DTT) for up to $2 \mathrm{~h}$ and levels of p90ATF6 and p50ATF6 were evaluated by Western blot analysis. Protein level of $\beta$-actin is shown at the bottom as a loading control. (b) Cells were exposed to $\mathrm{CdCl}_{2}$ in the absence $(-)$ or presence $(+)$ of $300 \mu \mathrm{M}$ AEBSF for $3 \mathrm{~h}$ and subjected to Western blot analysis of ATF6. (c) Cells were exposed to $\mathrm{CdCl}_{2}$ in the presence of $0-300 \mu \mathrm{M}$ AEBSF for $4 \mathrm{~h}$ and subjected to Hoechst staining. Asterisks indicate statistically significant differences $(P<0.05)$. (d) LLCPK1 cells were transiently transfected with EGFP together with an empty plasmid (Mock) or an expression plasmid for a dominant-negative mutant of ATF6 (ATF6DN) and exposed to $\mathrm{CdCl}_{2}$ for $6 \mathrm{~h}$. Percentages of EGFP-positive round cells against total EGFP-positive cells were evaluated by fluorescence microscopy. An asterisk indicates a statistically significant difference $(P<0.05)$. (e) Cells were exposed to $\mathrm{CdCl}_{2}$ in the presence of $0-300 \mu \mathrm{M}$ AEBSF for $4 \mathrm{~h}$ and subjected to Northern blot analysis of $C H O P$. Densitometric analysis of individual mRNAs is shown at the bottom. (f) LLC-PK1 cells were transiently transfected with EGFP together with a gene coding for a dominant-negative mutant of CHOP (CHOP-DN) and exposed to $\mathrm{CdCl}_{2}$ for $6 \mathrm{~h}$. Percentages of apoptotic cells were evaluated by fluorescence microscopy

tubular cells. Western blot analysis revealed that phosphorylation of JNK was substantially induced within $1 \mathrm{~h}$, peaked at $1.5-2 \mathrm{~h}$ and declined after $4 \mathrm{~h}$ (Figure 6e). To exclude a possibility that activation of JNK could be caused through other proapoptotic UPR, especially the ATF6 pathway, LLC-PK1 cells were treated with $\mathrm{CdCl}_{2}$ in the absence or presence of AEBSF and activation of JNK was retested. As shown in Supplementary Figure 4c, phosphorylation of JNK by $\mathrm{CdCl}_{2}$ was not attenuated by blockade of the ATF6 pathway. a

b Clone No. $\frac{\text { LL/Mock }}{3} \frac{L L / X B P 1-D N}{720}$

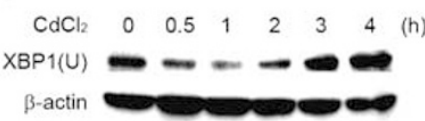

XBP1-DN

GAPDH $=$

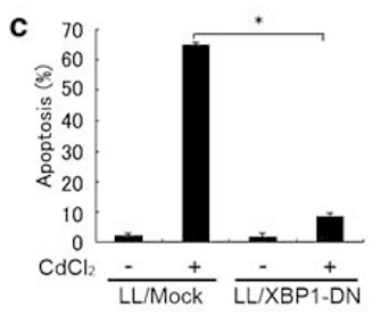

d $\mathrm{CdCl}_{2} \frac{\mathrm{LL} / \mathrm{Mock}}{-+} \frac{\mathrm{LL} / \mathrm{XBP} 1-\mathrm{DN}}{-+}$

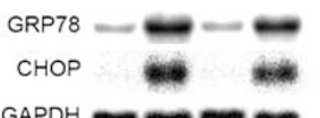

GAPDH

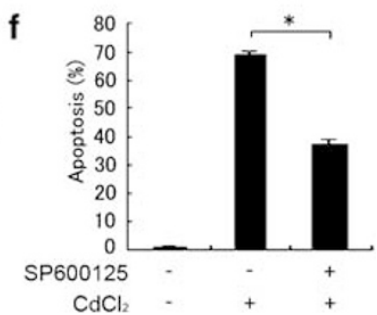

Figure 6 Activation of the IRE1-XBP1 pathway and JNK by cadmium. (a) LLCPK1 cells were stably transfected with a gene encoding FLAG-tagged XBP1(U) and established transfectants were treated with $20 \mu \mathrm{M} \mathrm{CdCl}_{2}$ for up to $4 \mathrm{~h}$. Western blot analysis of XBP1(U) was performed using an anti-FLAG antibody. (b-d) LLC-PK1 cells were stably transfected with a gene coding for XBP1-DN and LL/XBP1-DN cells were established. (b) Northern blot analysis of XBP1-DN expression. (c) Cells were treated with $\mathrm{CdCl}_{2}$ for $4 \mathrm{~h}$ and subjected to Hoechst staining. An asterisk indicates a statistically significant difference $(P<0.05)$. (d) Transfectants were treated with $\mathrm{CdCl}_{2}$ for $6 \mathrm{~h}$ and subjected to Northern blot analysis of GRP78 and CHOP. (e) LLC-PK1 cells were treated with $\mathrm{CdCl}_{2}$ for up to $4 \mathrm{~h}$ and subjected to Western blot analysis of phosphorylated JNK and total JNK. (f) LLC-PK1 cells were treated with $\mathrm{CdCl}_{2}$ for $4 \mathrm{~h}$ in the absence (-) or presence (+) of $10 \mu \mathrm{M} \mathrm{SP} 600125$ and subjected to Hoechst staining. An asterisk indicates a statistically significant difference $(P<0.05)$

To examine a role of JNK in cadmium-induced apoptosis, LLC-PK1 cells were pretreated with an inhibitor of JNK, SP600125, and exposed to $\mathrm{CdCl}_{2}$. Microscopic analysis revealed that SP600125 substantially attenuated $\mathrm{CdCl}_{2}$ induced cellular damage (Supplementary Figure 4d). Hoechst staining showed that blockade of JNK activation significantly inhibited induction of apoptosis approximately by $46 \%$ (from $69.0 \pm 1.5$ to $37.0 \pm 2.0 \% ; P<0.05$ ) (Figure $6 \mathrm{f}$ ). These results suggested crucial, major roles of the IRE1-XBP1 pathway and $\mathrm{JNK}$ in $\mathrm{CdCl}_{2}$-induced apoptosis of renal tubular cells.

\section{Discussion}

In the present study, we demonstrated involvement of ER stress in cadmium-induced apoptosis. In LLC-PK1 cells, cadmium induced ER stress and attenuation of ER stress by ER chaperones inhibited apoptosis. After exposure to cadmium, PERK, ATF6 and IRE1 were activated and the ATF6 and IRE1 pathways contributed to apoptosis. Induction of CHOP, activation of XBP1 and phosphorylation of JNK were identified as possible downstream events responsible for apoptosis. In contrast, the PERK-elF2 $\alpha$ pathway was found to be antiapoptotic and counteracted the proapoptotic signals. These results evidenced for the first time that cadmium-induced apoptosis of renal tubular cells is mediated, 
at least in part, by ER stress and that atypical, bidirectional regulation of apoptosis via distinct UPR is implicated in the apoptotic process. The outline of our current hypothesis is illustrated in Figure 7.

Previous reports indicated that cadmium may induce apoptosis through altered activity of protein kinases, phosphatases and transcription factors, generation of ROS, induction of mitochondrial pathways or activation of caspases. $^{32}$ Mechanisms involved may be different from cell type to cell type, but among those, mitochondria have been regarded as the crucial target of cadmium. For example, although cadmium has the potential for activating various protein kinases, it induced apoptosis through disruption of the mitochondrial membrane, cytochrome $c$ release and activation of caspase- 9 independent of protein kinase $A$, protein kinase $C$ and mitogen-activated protein kinases in glioma cells. ${ }^{33}$ Similarly, in proximal renal tubular cells, the mitochondrial pathway is also considered as a pathway responsible for cadmium-triggered apoptosis. ${ }^{10}$ However, no information was available regarding whether and how the ER, another crucial organelle that transduces proapoptotic signals, is involved in cadmium-induced apoptosis of tubular cells. In the present study, we provided evidence that ER is also a critical player. Currently, the relationship between the mitochondrial pathway and the ER pathway is unclear. Both proapoptotic pathways may be independently induced, as suggested in glioma cells treated by $\mathrm{N}$-(4-hydroxyphenyl)retinamide. ${ }^{34}$ Alternatively, ER stress might be an upstream or a downstream event involved in the mitochondria-ROS pathway. Recently, we found that antioxidant $\mathrm{N}$-acetylcysteine significantly attenuated ER stress and apoptosis caused by cadmium, supporting the latter possibility (our unpublished observation).

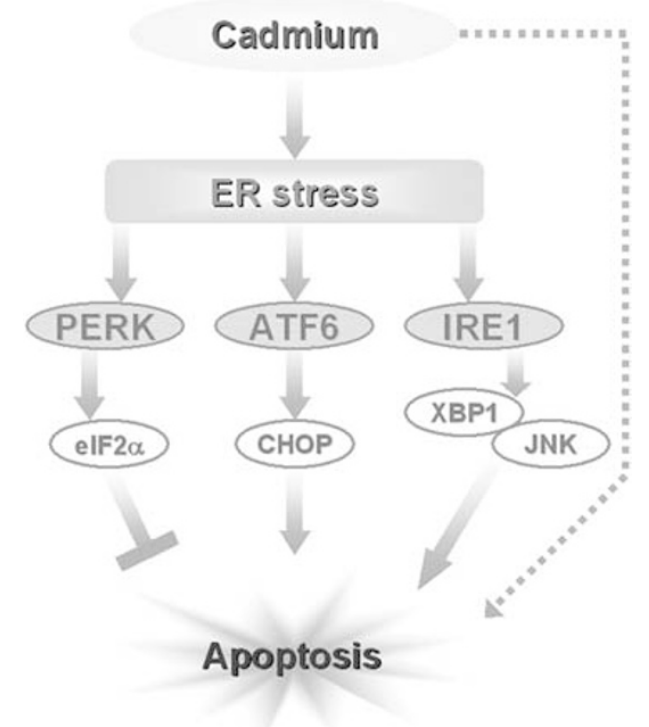

Figure 7 Current hypothesis on the induction of ER stress and consequent apoptosis by cadmium in renal tubular epithelial cells. Cadmium induces ER stress and causes activation of PERK, ATF6 and IRE1. The ATF6 pathway contributes to apoptosis via induction of CHOP and the IRE1 pathway induces apoptosis via activation of XBP1 and phosphorylation of JNK. In contrast, the PERK-elF2 $\alpha$ pathway is antiapoptotic and counteracted the proapoptotic signals
Induction of GRP78 by cadmium may be observed in some tumor cells. ${ }^{35,36}$ However, to date, little has been disclosed about which UPR is transduced by cadmium and whether and how individual signals contribute to apoptosis. In the present study, we first showed that, in response to $\mathrm{CdCl}_{2}$, phosphorylation of PERK was induced in tubular epithelial cells. This is consistent with a previous report showing that elF2 $\alpha$ was phosphorylated by cadmium in vitro using reticulocyte lysate. $^{37}$ In general, the PERK-elF2 $\alpha$ pathway transduces proapoptotic signals, for example, induction of $\mathrm{CHOP}$ via translation of ATF4. ${ }^{27}$ However, unexpectedly, we found that the PERK-elF2 $\alpha$ pathway was antiapoptotic in cadmiumexposed tubular cells. In some particular situations, GRP78 may be upregulated by ATF4. However, the cytoprotective effect of the PERK-elF2 $\alpha$ pathway was independent of upregulation of GRP78, as shown in this report. It is in contrast to a recent report implying that phosphorylation of elF2 $\alpha$ and resultant translation of ATF4 could be responsible for the induction of GRP78 by cadmium in renal tubular cells. ${ }^{38}$ It is known that the PERK-elF2 $\alpha$ pathway can relieve ER stress via translational suppression. ${ }^{15}$ The antiapoptotic effect of the PERK-elF2 $\alpha$ pathway may be ascribed to the attenuation of ER stress simply by general inhibition of protein production.

We showed that the ATF6 pathway was induced by cadmium and that, in contrast to several other previous reports, this pathway was found to be proapoptotic in cadmium-exposed tubular cells. In general, the ATF6 pathway is considered as an important antiapoptotic machinery against ER stress because it induces several ER resident chaperones, including GRP78, via activation of ERSE. ${ }^{21}$ Indeed, suppression of ATF6 by AEBSF reduced induction of GRP78 by cadmium in a dose-dependent manner (Supplementary Figure 5). Currently, molecular mechanisms involved in the proapoptotic action of ATF6 has not been elucidated completely, but we found that induction of CHOP was caused not by the PERK-elF $2 \alpha$ pathway but by the ATF6 pathway and thereby contributed to cadmiumtriggered apoptosis.

In the present report, we also showed the IRE1 pathway contributed to cadmium-induced apoptosis. In general, the IRE1 pathway is considered as a proapoptotic pathway via activation of ASK1 and JNK. Indeed, we observed that JNK was rapidly activated following exposure to cadmium and its suppression attenuated apoptosis. However, we also found that cadmium induced activation of the IRE1-XBP1 pathway and that dominant-negative inhibition of XBP1 markedly attenuated apoptosis. The proapoptotic effect of XBP1 was dependent neither on suppression of GRP78 nor on induction of $C H O P$. This was unexpected because, generally, XBP1 is considered as an antiapoptotic transcription factor that triggers induction of ER chaperones and other genes involved in ER-associated protein degradation. ${ }^{39,40}$ To our knowledge, this is the first to demonstrate the proapoptotic property of XBP1 in mammalian cells. Currently, it is unclear how XBP1 contributes to cadmium-triggered apoptosis. Our preliminary data indicated a possibility that activation of JNK may be an event downstream of XBP1 (unpublished observation).

In this report, we elucidated contribution of ER stress to cadmium-induced apoptosis of tubular cells. Further investigation will be required to elucidate relationship among 
oxidative, mitochondrial and ER stress during the process of cadmium-induced apoptosis. In addition, the fact that ER stress was triggered by several other nephrotoxic metals (Supplementary Figures $1 \mathrm{a}$ and $\mathrm{b}$ ) indicates a possibility that the similar mechanism identified here may be applied generally for metal-induced renal injury.

\section{Materials and Methods}

Data are provided as Supplementary materials.

Acknowledgements. M Yokouchi and N Hiramatsu equally contributed to this work. We appreciate Dr. Richard C Austin (Henderson Research Center), Dr. Satoshi Ogawa (Kanazawa University), Dr. Ron Prywes (Columbia University), Dr. Kazunori Imaizumi (Nara Institute of Science and Technology), Dr. Amy S Lee (University of South California), Dr. Laurie H Glimcher (Harvard Medical School), Dr. David Ron (New York University School of Medicine), Dr. Akihiro Tomida (Japanese Foundation of Cancer Research), Dr. Kazutoshi Mori (Kyoto University) and Dr. Hidetoshi Hayashi (Nagoya City University) for kindly providing us with plasmids. This work was supported, in part, by Grant-in-Aids for Scientific Research from the Ministry of Education, Culture, Sports, Science and Technology, Japan (no. 16390243, no. 17651026) to M Kitamura.

1. IPCS (International Programme on Chemical Safety) Cadmium Environmental Health Criteria 134. Geneva: World Health Organization, 1992.

2. Lind $\mathrm{Y}$, Engman J, Jorhem L, Glynn AW. Cadmium accumulation in liver and kidney of mice exposed to the same weekly cadmium dose continuously or once a week. Food Chem Toxicol 1997; 35: 891-895.

3. Nogawa K. Itai-itai disease and follow-up studies. In: Nriagu JO, (Ed) Cadmium in the Environment. New York: John Wiley and Son, 1981. pp. 1-37.

4. Gambaro G, Verlato F, Budakovic A, Casara D, Saladini G, Del Prete D et al. Renal impairment in chronic cigarette smokers. J Am Soc Nephrol 1998; 9: 562-567.

5. Bernard A. Renal dysfunction induced by cadmium: biomarkers of critical effects. Bio Metals 2004; 17: 519-523.

6. Prozialeck WC, Wellington DR, Mosher TL, Lamar PC, Laddaga RA. The cadmiuminduced disruption of tight junctions in LLC-PK1 cells does not result from apoptosis. Life Sci 1995; 57: 199-204.

7. Jeong SH, Habeebu SS, Klaassen CD. Cadmium decreases gap junctional intercellular communication in mouse liver. Toxicol Sci 2000; 57: 156-166.

8. Prozialeck WC, Lamar PC. Effects of glutathione depletion on the cytotoxic actions of cadmium in LLC-PK1 cells. Toxicol Appl Pharmacol 1995; 134: 285-295.

9. Hamada T, Nakano S, Iwai S, Tanimoto A, Ariyoshi K, Koide O. Pathological study on beagles after long-term oral administration of cadmium. Toxicol Pathol 1991; 19: $138-147$.

10. Thevenod F. Nephrotoxicity and the proximal tubule. Insights from cadmium. Nephron Physiol 2003; 93: 87-93.

11. Ishido M, Tohyama C, Suzuki T. C-Myc is not involved in cadmium-elicited apoptotic pathway in porcine kidney LLC-PK1 cells. Life Sci 1998; 63: 1195-1204.

12. Ishido M, Suzuki T, Adachi T, Kunimoto M. Zinc stimulates DNA synthesis during its antiapoptotic action independently with increments of an antiapoptotic protein, $\mathrm{Bcl}-2$, in porcine kidney LLC-PK1 cells. J Pharmacol Exp Ther 1999; 290: 923-928.

13. Xie J, Shaikh ZA. Cadmium-induced apoptosis in rat kidney epithelial cells involves modulation of NF- $\kappa$ B activity. Toxicol Sci 2006; 224: 56-65.

14. Lee AS. The glucose-regulated proteins: stress induction and clinical applications. Trends Biochem Sci 2001; 26: 504-510.

15. Kaufman RJ. Orchestrating the unfolded protein response in health and disease. $J$ Clin Invest 2002; 110: 1389-1398.

16. Chun HS, Lee H, Son JH. Manganese induces endoplasmic reticulum (ER) stress and activates multiple caspases in nigral dopaminergic neuronal cells, SN4741. Neurosci Lett 2001; 316: 5-8.

17. Qian $\mathrm{Y}$, Falahatpisheh $\mathrm{MH}$, Zheng $\mathrm{Y}$, Ramos KS, Tiffany-Castiglioni E. Induction of $78 \mathrm{kD}$ glucose-regulated protein (GRP78) expression and redox-regulated trans- cription factor activity by lead and mercury in C6 rat glioma cells. Neurotox Res 2001; 3 : 581-589.

18. Qian Y, Tiffany-Castiglioni E. Lead-induced endoplasmic reticulum (ER) stress responses in the nervous system. Neurochem Res 2003; 28: 153-162.

19. Lorz C, Justo P, Sanz A, Subira D, Egido J, Ortiz A. Paracetamol-induced renal tubular injury: a role for ER stress. J Am Soc Nephrol 2004; 15: 380-389.

20. Liu H, Baliga R. Endoplasmic reticulum stress-associated caspase 12 mediates cisplatininduced LLC-PK1 cell apoptosis. J Am Soc Nephrol 2005; 16: 1985-1992.

21. Rutkowski DT, Kaufman RJ. A trip to the ER: coping with stress. Trends Cell Biol 2004; 14 $20-28$.

22. Hiramatsu N, Kasai A, Hayakawa K, Yao J, Kitamura M. Real-time detection and continuous monitoring of ER stress in vitro and in vivo by ES-TRAP: evidence for systemic, transient ER stress during endotoxemia. Nucleic Acids Res 2006; 34: e13 (1-12).

23. Ozawa K, Kuwabara K, Tamatani M, Takatsuji K, Tsukamoto Y, Kaneda S et al. 150-kDa oxygen-regulated protein (ORP150) suppresses hypoxia-induced apoptotic cell death. J Biol Chem 1999; 274: 6397-6404.

24. Kitao Y, Ozawa K, Miyazaki M, Tamatani M, Kobayashi T, Yanagi H et al. Expression of the endoplasmic reticulum molecular chaperone (ORP150) rescues hippocampal neurons from glutamate toxicity. J Clin Invest 2001; 108: 1439-1450.

25. Nakatani $\mathrm{Y}$, Kaneto H, Kawamori D, Yoshiuchi K, Hatazaki M, Matsuoka TA et al. Involvement of endoplasmic reticulum stress in insulin resistance and diabetes. J Biol Chem 2005; 280: 847-851.

26. Boyce M, Bryant KF, Jousse C, Long K, Harding HP, Scheuner D et al. A selective inhibitor of elF2 $\alpha$ dephosphorylation protects cells from ER stress. Science 2005; 307: 935-939.

27. Harding HP, Novoa I, Zhang Y, Zeng H, Wek R, Schapira M et al. Regulated translation initiation controls stress-induced gene expression in mammalian cells. Mol Cell 2000; 6 : 1099-1108.

28. Luo S, Baumeister P, Yang S, Abcouwer SF, Lee AS. Induction of Grp78/BiP by translational block: activation of the Grp78 promoter by ATF4 through and upstream ATF/ CRE site independent of the endoplasmic reticulum stress elements. J Biol Chem 2003; 278: 37375-37385.

29. Okada T, Haze K, Nadanaka S, Yoshida H, Seidah NG, Hirano Y et al. A serine protease inhibitor prevents endoplasmic reticulum stress-induced cleavage but not transport of the membrane-bound transcription factor ATF6. J Biol Chem 2003; 278: 31024-31032.

30. Gotoh T, Oyadomari S, Mori K, Mori M. Nitric oxide-induced apoptosis in RAW 264.7 macrophages is mediated by endoplasmic reticulum stress pathway involving ATF6 and CHOP. J Biol Chem 2002; 277: 12343-12350.

31. Urano F, Wang X, Bertolotti A, Zhang Y, Chung P, Harding HP et al. Coupling of stress in the ER to activation of JNK protein kinases by transmembrane protein kinase IRE1. Science 2000; 287: 664-666.

32. Pulido MD, Parrish AR. Metal-induced apoptosis: mechanisms. Mutat Res 2003; 533 227-241.

33. Habeebu SS, Liu J, Klaassen CD. Cadmium-induced apoptosis in mouse liver. Toxicol Appl Pharmacol 1998; 149: 203-209.

34. Tiwari M, Kumar A, Sinha RA, Shrivastava A, Balapure AK, Sharma R et al. Mechanism of 4-HPR induced apoptosis in glioma cells: evidences suggesting role of mitochondrial-mediated pathway and endoplasmic reticulum stress. Carcinogenesis 2006; 27 2047-2058.

35. Cigliano S, Remondelli P, Minichiello L, Mellone MC, Martire G, Bonatti S et al. Analysis of metal-regulated metallothionein and heat shock gene expression in HeLa-derived cadmium-resistant cells. Exp Cell Res 1996; 228: 173-180.

36. Tchounwou PB, Ishaque AB, Schneider J. Cytotoxicity and transcriptional activation of stress genes in human liver carcinoma cells (HepG2) exposed to cadmium chloride. Mol Cell Biochem 2001; 222: 21-28.

37. Hurst R, Schatz JR, Matts RL. Inhibition of rabbit reticulocyte lysate protein synthesis by heavy metal ions involves the phosphorylation of the $\alpha$-subunit of the eukaryotic initiation factor 2. J Biol Chem 1987; 262: 15939-15945.

38. Liu F, Inageda K, Nishitai G, Matsuoka M. Cadmium induces the expression of Grp78, an endoplasmic reticulum molecular chaperone, in LLC-PK1 renal epithelial cells. Environ Health Perspect 2006; 114: 859-864.

39. Lee AH, Iwakoshi NN, Glimcher LH. XBP-1 regulates a subset of endoplasmic reticulum resident chaperone genes in the unfolded protein response. Mol Cell Biol 2003; 23: 7448-7459.

40. Yoshida H, Matsui T, Hosokawa N, Kaufman RJ, Nagata K, Mori K. A timedependent phase shift in the mammalian unfolded protein response. Dev Cell 2003; 4 265-271.

Supplementary Information accompanies the paper on Cell Death and Differentiation website (http://www.nature.com/cdd) 